\title{
Revisión de la heteronomía en diálogo con P. Ricoeur
}

\author{
JUAN MASIÁ CLAVEL \\ Universidad de Comillas, Madrid
}

En su obra El Si-mismo como un Otro P. Ricoeur se centra en la pregunta "¿quién?»: ¿quién habla?, ¿quién actúa?, ¿quién es el sujeto de la narraciôn?, ¿quién es el sujeto de la imputación? Tratando de evitar tanto la exaltación cartesiana como la humillación nietzscheana del sujeto, da Ricoeur el rodeo hermenéutico de pasar por las teorías del lenguaje, de la acción, de la narratividad y de la ética. El «Sí-mismon, más que un punto de partida, resulta ser un punto de llegada tras el rodeo de sus expresiones. Este esfuerzo de recuperación del sujeto y su autonomía pasando por el otro puede concebirse como una revisión de la heterono- mía. Hay una estructura dual de la conciencia - voz que llama y voz que responde - desplegada en forma de estructura dialogal de la vida humana. Hay una alteridad constitutiva del "Sí-mismo" (al que no se llama "yo" porque decir "Soi» es más que decir «je»). En relación dialéctica con esa alteridad se constituye la ipseidad. El Sí-mismo y el otro se implican mutuamente. Cada uno de ellos son un yo, un tú y un élella, vinculados correlativamente para ser autónomos. Tal concepción de sí mismo a la luz del otro supone una revisión de la heteronomía, así como de la misma autonomía.

La palabra "heteronomía" no tiene buena prensa. Sugiere conformismo, imposición de una ley desde fuera, represión, coerción, etc. Desde la Ilustración, el sapere aude kantiano ha pesado mucho para dar el mejor sentido a la autonomía, a la autolegislación del que piensa y decide por sí mismo. Sin embargo, los cuestionamientos posteriores de la autonomía y de las modernas hybris del sujeto han preparado el terreno para repensar con más amplitud y profundidad la heteronomía.

El título mismo de la última obra de Ricoeur, El Si-mismo como un Otro, sugiere una autonomía heteronómica y una heteronomía autonómica. Una autonomía en la que, dicho con su terminología, no se da el «Símismo" sin una dialéctica de ipseidad y alteridad. En este sentido, no se trata en esta obra de una vuelta al sujeto estrecho de algunos enfoques de la modernidad, sino de un intento, más allá de la modernidad y de sus críticos, de recuperación del sujeto. $\mathrm{O}$ más bien, de preguntarse qué clase de recuperación del sujeto es posible hoy día. 


\section{Entre la exaltación y la humillación del sujeto}

Ricoeur ha tratado, como dice en la introducción a dicha obra, de evitar tanto la exaltación cartesiana de la subjetividad, como la crítica que lleva hasta el extremo la humillación del sujeto mediante la sospecha al estilo de Nietzsche. El título de las conferencias pronunciadas en la Universidad de Edimburgo por P. Ricoeur en 1986 (Gifford Lectures) era On Selfhood, the Question of Personal Identity. El título de la obra publicada recientemente en francés es Soi-même comme un autre. ${ }^{1}$ Como explica el autor, este título expresa la convergencia de tres preocupaciones filosóficas que han motivado la investigación llevada a cabo en los diez estudios que componen la obra.

Al decir "Sí-mismo», en vez de decir "yo", quiere insistir Ricoeur en el "primado de la mediación reflexiva sobre la posición inmediata del sujeto». Al colocar unidos por un guión el «Soi» y el "même», trata de "disociar dos significaciones mayores de la identidad $":^{2}$ la identidad en el sentido del idem - ser el mismo que permanece en el tiempo- y la identidad en el sentido del ipse - - -ser uno mismo, por ejemplo el «Sí-mismo» mantenedor de una promesa-. Al hablar del "Sí-mismo como otro», este "como" - que Ricoeur parafrasea sen tanto que, en cuanto otro"- apunta a la dialéctica entre el sí mismo (Soi) y el otro que uno mismo (autre que Soi). Se subraya así la íntima conexión e implicación de la alteridad y la ipseidad.

Son, en resumen, tres las perspectivas básicas de la obra. En primer lugar, se trata de buscar para el Soi un estatuto que cscape al dilema entre exaltación o humillación del sujeto en las filosofías del cogito en primera persona. Para Ricoeur decir Soi es más que decir je. Soi es, dice, el reflexivo de todas las personas gramaticales. Empalmando el estilo analítico y el de la fenomenología hermenéutica, dará Ricoeur rodeos (détour) de análisis y reflexión para explorar las diversas maneras de responder a la pregunta «quién». En segundo lugar, le preocupa disociar dos sentidos de identidad: idem (gleich, same, mismidad, permanencia temporal...) e ipse (Selbst, Self, ipseidad, el "qué» del "quién»...) En tercer lugar, a medida que avanza la obra, se profundiza en la dialéctica del «Mismo» y el «Otro». Son muchas las maneras de decirse el "sí mismo" como o en tanto que otro.

\section{Maneras de hacer la pregunta "¿Quién?"}

En estos rodeos hermenéuticos sucesivos, Ricoeur se pregunta quién es el sujeto que habla y se autodesigna al hablar, quién es el sujeto de la acción, quién es el sujeto de la narración y quién es el sujeto de la imputación.

El primer rodeo de la hermenéutica para acercarse indirectamente a 
la identidad del sujeto, al Sí-mismo personal, es el rodeo que pasa por las teorías del lenguaje. Pasando por el doble desvío de la semántica y la pragmática se acerca a la pregunta que hace de hilo conductor de toda la obra: "¿Quién?». En esta primera etapa la pregunta se desdobla en las dos preguntas siguientes: «QQuién es el sujeto de quien se habla cuando se designa, mediante la referencia identificante, a una persona como distinta de una cosa?», y «¿Quién es el sujeto que habla autodesignándose a sí mismo como locutor que dirige la palabra a un interlocutor?". Se pregunta $\mathrm{Ri}$ coeur cómo puede el «Soi» ser a la vez una persona de la que se habla y un sujeto que se autodesigna en primera persona dirigiéndose a una segunda persona, ${ }^{3}$ y como puede una tercera persona ser designada en el discurso como alguien que se autodesigna en primera persona. ${ }^{4} \mathrm{El}$ problema central en los dos primeros estudios es cómo el "yo-tú" de la interlocución puede exteriorizarse en un «él» sin perder la capacidad de autodesignarse, y cómo el «él-ella» de la referencia identificante puede interiorizarse en un sujeto que se dice a sí mismo. ${ }^{5}$ ¿Qué clase de ser es éste, se pregunta, que se presta a una doble identificación, como persona objetiva y como sujeto que reflexiona?

El segundo rodeo de la hermenéutica para acercarse indirectamente a la identidad del sujeto es el rodeo que pasa por las teorías sobre la acción humana. En este segundo rodeo nos acercamos a la pregunta «¿quién?» a través de la pregunta por el sujeto de la acción: «qquién actúa y por qué lo hace?» serian las preguntas que nos pongan en camino hacia la pregunta "¿quién es el que hace, quién es el que actúa?. Y, en el fondo de estas preguntas, a lo que va Ricoeur es a preguntar qué nos enseña la acción sobre el agente y cómo nos ayuda esto a ahondar más en la distinción entre idem e ipse. ${ }^{6}$

\section{La necesidad de narrar y de leer}

Los estudios 5 y 6 de la obra vuelven a tomar la temática de Tiempo y narración, pero aquí lo que le preocupa a Ricoeur primordialmente no es la constitución del tiempo sino del sujeto. Este tercer rodeo de la hermenéutica para acercarse a la identidad del sujeto es el rodeo que pasa por las teorías de la narratividad. Pone de relieve una dimensión muy importante que había quedado entre paréntesis en los dos rodeos de los cuatro estudios primeros: la dimensión temporal, tanto del "Sí-mismo" como de la misma acción. Se pone aquí especialmente de manifiesto la distinción entre identidad como idem e identidad como ipse. Y, además, sirve este tercer rodeo - contar, narrar- de charnela entre los dos anteriores - describir-y el siguiente rodeo, el cuarto - prescribir-, que se ocupará de la dimensión ética.

Insiste Ricoeur en la función mimética del relato que imita la vida. 
Pero, al entrar el relato en el campo de la ficción, opera, separándose de la vida, una nueva ruptura entre vida y literatura. La lectura hará que se encuentren de nuevo. En la lectura se da, según Ricoeur, una lucha entre dos estrategias: ${ }^{7}$ a) la estrategia de seducción, conducida por el autor bajo la guisa de un narrador más o menos digno de confianza, con la complicidad del lector que, al entrar en la lectura, pone gustosamente entre paréntesis su incredulidad, $b$ ) una estrategia de sospecha, conducida por el lector despierto que no ignora que, en el fondo, es él mismo el que eleva el relato a la significatividad supliendo las lagunas más o menos pretendidas del texto. Pero ahora añade Ricoeur algo más a lo que ya había dicho sobre esto en Tiempo y narración. La condición de posibilidad de la aplicación de la literatura a la vida reposa, dice, por lo que se refiere a la dialéctica del personaje, en el problema de identificarnos con él. Esta identificación con el personaje forma parte de nuestro carácter. Al identificarnos con el héroe del relato, contribuye así el relato a la narrativización de nuestro carácter.

Pero lo que más nos interesa subrayar para el presente estudio es que Ricoeur coloca, como vimos, la teoría narrativa como charnela que articule el tránsito desde el mundo del describir al del prescribir. La noción de identidad narrativa le sirve como idea directriz para ensanchar el campo de lo práctico hasta un alcance mucho mayor que el de las acciones simples descritas, en diálogo con las filosofías analíticas, en los cuatro primeros estudios de la obra a partir de las teorías de la acción. "Narrar, dice, es desplegar un espacio imaginario donde puedan tener lugar experiencias de pensamiento en las que el juicio moral se ejerza desde una modalidad hipotética.» ${ }^{8}$

\section{El problema ético: del optativo al interrogativo pasando por el imperativo}

El cuarto rodeo de la hermenéutica para acercarse indirectamente a la identidad del sujeto es el rodeo que pasa por las teorías éticas de la acción. Ahora la pregunta es por el sujeto a quien puede imputarse la responsabilidad de la acción. La característica de este cuarto rodeo es poner de relieve la dialéctica del "mismo" y el "otro», de la ipseidad y la alteridad. Aquí va a aparecer la autonomía del sujeto personal íntimamente ligada a la preocupación por el prójimo - la sollicitude - y a la justicia para con todos y cada uno de nuestros semejantes. No quiere reducirse a la sola relación cara a cara con el otro, sino tener en cuenta que el otro y yo estamos dentro de instituciones. Define lo esencial de la eticidad como «el deseo de la vida buena, con y para otros, dentro de instituciones justas». Le preocupa el problema del mal, del que ya se había ocupado en $L a$ simbólica det mal, pero ahora lo hace con un énfasis en el sufrimiento, ya que le parece que estamos en lo que él llama «el siglo de las víctimas inocentes». 
Ricoeur reserva convencionalmente el término "ética" para referirse al proyecto de la "vida buena" y el término "moral" para la articulación de este proyecto en normas universales y obligatorias. Dos dificultades surgen de esta distinción que, a mi parecer, no dejan que resalte con toda su fuerza lo mejor de estos capítulos. En primer lugar, se ha discutido tanto y es tan diverso el uso, según los autores, de los términos "ética» y "moral", que se presta paradójicamente a confusión el separarlos con tanta nitidez como intenta hacer Ricoeur en estos capítulos. En segundo lugar, parece sugerirse una excesiva dicotomía entre la herencia teleológica aristotélica y la herencia deontológica kantiana. Creo que ayudaría para entender mejor estos capítulos - 7,8 y 9 de la obra- el centrarnos en el contenido, sin preocuparnos excesivamente de esta distinción entre ética y moral, de la que el mismo Ricoeur dice que es convencional. También ayudaría el no exagerar la dicotomía entre lo teleológico y lo deontológico. Él mismo reconoce que no está aquí preocupado de ortodoxia aristotélica o kantiana.

La formulación del presente subtítulo - del optativo al interrogativo pasando por el imperativo- es mi paráfrasis, en un intento de hacer resaltar el contenido sin tropezar en problemas de terminología. En todo caso, para Ricoeur hay tres momentos en la eticidad: el deseo, la norma y la sabiduría práctica o prudencia. Al decir que lo optativo prevalece sobre lo imperativo parafraseo la afirmación de Ricoeur acerca de que el proyecto de la vida buena tiene primacía sobre el deber y la norma. ${ }^{9}$ Pero lo optativo necesita complementarse con lo imperativo que, a su vez, se subordina a el. Es decir, en términos de Ricoeur, que el proyecto ético ( $v i$ sée) necesita pasar por la prueba de la norma para depurarse. ${ }^{10}$ Finalmente, en el callejón sin salida en que nos hallamos atrapados entre la espada de la norma y la pared de la situación (en mi paráfrasis, lo interrogativo), hay que recurrir de nuevo al proyecto originario para hallar salida. Ante las limitaciones de lo imperativo volvemos a lo optativo pasando por lo interrogativo." 1

Notemos que la relación con las normas aparece en segundo lugar, pero no es por eso secundaria, sino imprescindible. Para Ricoeur, el proyecto ético se realiza y pone a prueba precisamente llevando a cabo las normas y pasando por ellas, no al margen de ellas. Están llamados a complementarse lo optativo y lo imperativo. Se nos impone la importancia de lo imperativo cuando confrontamos la necesidad de poner un freno a la violencia. Desde nuestra experiencia histórica se pone de relieve la necesidad y la importancia de lo imperativo. Pero no podemos olvidar que su marco de referencia es lo optativo, el proyecto originario de vida buena en que se realiza el sujeto.

$\mathrm{El}$ acento en este esquema triple -optativo, imperativo, interrogativo- impide, ante todo, que arranquemos como punto de partida del lega- 
lismo moralizador. No se pone al comienzo la ley moral, sino la aspiración originaria que Ricoeur llama visée éthique. En ella se encarnará posteriormente todo el mundo de las normas. Además, se tiene la ventaja de no quedar encerrado en un dilema entre enfoques de la ética teleológicos y deontológicos. Simplemente, se formula y resume el proyecto ético en tres puntos: «proyecto de vida buena, con y para los otros, en instituciones justas».12

Está claro que Ricoeur busca la complementariedad de las tradiciones aristotélica y kantiana, además de la complementariedad de las raíces antropológico-ontológicas de la vida buena y de la justicia: «La autonomía del Sí-mismo aparecerá ligada íntimamente a la solicitud por el prójimo y a la justicia para con cada unos.13 Paralelamente a lo que había hecho en los estudios anteriores, explora aquí Ricoeur la pregunta "quién». El "quién" del proyecto ético de vida buena es el sujeto de la autoestima. El "quién» del régimen de la norma es el sujeto que se autorrespeta. $\mathrm{El}$ "quién» de las aporías, confrontado con la limitación de las normas, retorna desde el autorrespeto a la autoestima, fuente de éste.

Es importante acentuar que no se limita Ricoeur a la relación interpersonal, pasando de la estima de sí a la solicitud por el otro. Incluye también lo institucional y el tema de la justicia. «El tomar en consideración la institución pertenece al proyecto ético tomado en toda su amplitud. No debía levantarse un muro entre individuo y sociedad impidiendo el paso del plano interpersonal al social. Una interpretación distributiva de la institución - pertenecer a, recibir parte de - contribuye a abatir ese muro y asegura la cohesión entre los componentes individuales, interpersonales y sociales de nuestro concepto de proyecto ético. $\aleph^{14}$ \& La igualdad es a la vida en las instituciones lo que la solicitud es a las relaciones interpersonales. La solicitud nos pone frente a un otro que es un rostro... La igualdad frente a un otro que es cada uno. ${ }^{15}$

\section{Por la alteridad a la ipseidad: revisión de la filosofía primera}

En el último estudio da Ricoeur tres pasos: $a$ ) recoge el peso ontológico de todos los estudios anteriores (los diversos rodeos) a partir del compromiso ontológico que lleva consigo el autotestimonio; $b$ ) recoge el peso ontológico de la distinción entre ipseidad y mismidad. Éste procede del anterior, ya que el autotestimonio es la certeza que cada uno tiene de existir como un idem en el sentido de la ipseidad; c) recoge el peso ontológico de la estructura dialéctica de la relación entre ipseidad y mismidad.

Cuando hablaba en los primeros estudios de "particulares básicos", dividiéndolos con Strawson en cosas y personas, estaba en un discurso de primer grado al que pertenecen categorías y existenciales. También hablaba a ese nivel cuando trataba de dar estatuto ético, y no meramente analí- 
tico-descriptivo, a la distinción persona-cosa con una fenomenología hermenéutica del Soi. Pero ahora, este décimo estudio, pasa a un discurso de segundo grado, más especulativo y ontológico, en el que se va a preguntar por la polisemia del ser del Soi en la dialéctica del Soi como ipse y como otro (autre que Soi). Al hablar de este modo de ipseidad y alteridad, formula Ricoeur una especie de metacategorías o grandes géneros, emparentados con el Mismo y el Otro platónicos, como él mismo dice. Sin embargo, se apresura a añadir que esta ipseidad y alteridad no se dejan tratar con una ontología prefabricada. Tratará de prolongar esa tradición de ontología, no repitiéndola, sino innovando creativamente y haciendo por desentrañar sus potencialidades.

Había comenzado ya esa búsqueda («vers quel ontologie?») incorporando (críticamente la certeza cartesiana y la sospecha nietzscheana, viendo en el prefacio de la obra el «autotestimonio" (attestation) como creencia, fianza y con-fianza. Había dado luego rodeos hermenéuticos para aproximarse desde diversos ángulos al autotestimonio y llevando cuidado en esos rodeos de mantenerse a igual distancia de la exaltación y la humillación del sujeto. Ahora, en este estudio final, al afirmar el carácter aléthico o veritativo del autotestimonio, ve Ricoeur abrirse un debate ontológico y no meramente epistémico. Ser verdadero y ser falso son, dice, para Aristóteles significaciones originales del ser. Pero Ricoeur trata de reunir, bajo el signo del ser como verdadero, lo dicho sobre el autotestimonio como creencia, fianza y con-fianza. No puede, entonces, limitarse a repetir la metacategoría verdadero-falso en sentido aristotélico; ha de repensarla. $\mathrm{E}$ introduce en el autotestimonio la sospecha.

El que el autotestimonio tenga por contrapartida la sospecha es un rasgo que separa el ser-verdadero según Aristóteles del ser-verdadero según una reflexión ontológica como la de Ricoeur. La sospecha ocuparía el lugar del ser-falso en el par aristotélico. Pero, para Ricoeur, la sospecha pertenece al mismo plano veritativo que el autotestimonio. Por eso es original la relación: no es sin más su contrario, como lo falso de lo verdadero. No se trata de una disyunción: o dar testimonio de sí o sospechar. No se trata de un dilema entre autotestimonio verdadero o falso. "La sospecha, dice, es también un camino hacia el autotestimonio y un pasadizo a través del autotestimonio. ${ }^{16} \mathrm{La}$ sospecha persigue al autotestimonio como el falso testimonio al verdadero. A lo largo de toda la obra ha aparecido esta adherencia de la sospecha al autotestimonio. "Una especie de equilibrio inquietante entre autotestimonio y sospecha se ha impuesto así cada vez que la certeza del So $i$ ha debido refugiarse en el recinto inexpugnable de la pregunta quién.. ${ }^{17}$ La razón profunda de esto -y por eso me alargo aquí en esta parte- es porque, según Ricoeur, aquello de lo que, últimamente, se da testimonio en el autotestimonio es una ipseidad; pero una ipseidad que, a la vez que se diferencia de la mismidad, está siempre en relación 
dialéctica con la alteridad. Por eso podemos concebir el intento de Ricocur como una revisión de la heteronomía, que es una recuperación del sujeto, y como una revisión de la autonomía, que es un reaprecio de la heteronomía. Lo que ocurre es que "hetero-» ya no significa "fuera" o "desde fuera», sino que es parte esencial del «auto-s.

Se responde con esta concepción a lo planteado al comienzo de la obra. Ricoeur parte, en su enfoque hermenéutico sobre el sujeto, de percatarse de que la crisis del sujeto, en vaivén entre su exaltación idealista y su humillación nihilista, nos urge a revisar el estatuto de la conciencia. Lo encuentra tratando de evitar una conciencia totalmente identificada con la verdad o una conciencia reducida a la ilusión por la sospecha. Esta vía media es, para Ricoeur, el autotestimonio de sí mismo como un otro. Una conciencia así no es un foco, origen de luz, sino una tarea de ir iluminando, y esta misión o destino de la conciencia es un momento de su fundamentación. Tendrá que sospechar siempre, pero sin olvidar que lo que le hace sospechar es el motor que la impele. Esa es para Ricoeur la preacupación que hace que el sujeto no deje de buscar su auténtico ser, dando testimonio de él en su hacer y padecer. Una conciencia así es más un punto de llegada que de partida, tras el rodeo de descifrar sus expresiones. Pasa por los otros momentos de sí, pasa por lo otro y los otros, pasa por las instituciones. $\mathrm{X}$ así se descubre, no sólo haciéndose, sino dejándose hacer, deshacer y rehacer. Esto lo hace el ser humano deseando ser y deseando apropiarse su ser, a la vez que tiene que vigilar para no perderlo. La reflexión con que ejerce esa vigilancia es para Ricoeur acto de interpretación: "La apropiación de nuestro esfuerzo por existir y de nuestro deseo de ser a través de las obras que dan testimonio de ese esfuerzo y de ese deseo*. ${ }^{18}$

\section{Revisión de la heteronomia}

Como acabamos de ver, en el estudio 10 , el último de la obra, ${ }^{19}$ hace Ricoeur un intento de ontología, conclusivo de los estudios anteriores. Trata de captar el sentido del ser humano como un ser agente y paciente sobre el telón de fondo de una manera de comprender el ser, repensando la problemática del acto y la potencia a la luz de la temática de la attestation (autotestimonio). Se da en este estudio todo su peso a la autonomía humana como responsabilidad y capacidad de respuesta; pero la manera de ser responsable no es a base de crear desde cero, sino respondiendo a un llamamiento que interpela la libertad. Acoge así el ser humano lo que da a la libertad la capacidad de ser y de realizarse. Dicho de otra manera, la libertad reconoce, en lo más profundo de sus iniciativas, una receptividad radical que la hace ser.

Para ser uno mismo hay que responder desde el fondo de la autono- 
mía a la voz de una "heteronomía" (llamémosla así convencionalmente) radical, a la que habría que llamar para ser exactos «auto-hetero-nomía» (la paráfrasis es mía). No es una heteronomía desde fuera, sino dentro de la misma autonomía. Hay una estructura dual de la conciencia, dos voces -la que llama y la que responde-, ambas dentro de sí mismo. Aquí radica lo que luego se despliega en la vida humana en forma de estructura dialogal de ésta.

Tal concepción de la libertad ya estaba en Ricoeur desde sus primeros escritos sobre filosofía de la voluntad. "La libertad no es un acto puro, la libertad es en cada uno de sus momentos, actividad y receptividad, se hace acogiendo lo que ella no hace: valores, poderes y naturaleza pura. En este sentido nuestra libertad es solamente humana. ${ }^{20}$

Hay una alteridad constitutiva del sujeto. No hay una autonomía total y exclusiva, ya que la libertad humana implica esencialmente la alteridad. $\mathrm{Y}$ esto de un modo tan compenetrado que no es posible pensar la una sin la otra. Una experiencia de pasividad fundamental está en el propio cuerpo. La libertad humana no crea desde cero. Es capacidad de acoger y asumir la oferta que le viene hecha por un cuerpo que no ha sido puesto por ella. Ya a nivel del cuerpo se nos remite de la autonomía a la heteronomía, ya en el cuerpo se insinúa lo trascendente, en la medida en que el cuerpo nos pone de manifiesto la índole receptiva de la libertad. No deja el cuerpo que la conciencia se encierre a solas consigo misma.

Por otra parte, los imperativos sociales me recuerdan que no estoy solo en el mundo. El otro me revela que el ser del sujeto no es solipsista. La corporeidad y la intersubjetividad descentran al sujeto. Muestran que el ser que es un Sí-mismo no es un ser aislado. Encarnado en un cuerpo y comunicando con otros, salgo de mí a mi cuerpo y al otro y rompo la ambición del yo. No está la característica del yo en poder romper con el mundo o con el otro. Sus límites son limitaciones fecundas que nos abren más allá. De mi cuerpo y del otro recibe la libertad estímulo para actuar. El límite me desengaña de la pretensión de constituirme en lo último, me abre a lo que se anuncia en el horizonte, se hace más profunda la existencia al ahondar en su limitación. Nos vemos y captamos - de nuevo la paráfrasis es mía- como centros limitados de orientación ilimitada. Se percata nuestra conciencia de que no es lo que se cree o quiere ser, sino que es para el ser que ella no es. El límite revela así el más allá del horizonte.

El énfasis en el otro ha sido descartado a veces demasiado fácilmente como heteronomía que se opondría a la autonomía. También ha sido, por otra parte, descartado a menudo el énfasis en la autonomía y se ha interpretado la autoestima como si se redujese a un egoísmo rechazable. Lo que aquí hemos llamado "revisión de la heteronomía", parafraseando a Ricoeur, nos lleva a una dialéctica del Soi y del autre. No se trata, en la 
autoestima de que habla Ricoeur, de amarse a sí mismo de modo exclusivista. «El amor de sí es la autoestima pervertida por la inclinación al mal. .21 Ricoeur hace un esfuerzo notable por articular los tres pronombres personales: yo, tú, él-ella, en un intento por ver al otro en mí y a mí en el otro, así como en cada uno de los otros -ellos-, y a cada uno de los otros en mí y en el otro. "22 "El Sí-mismo, decía en su curso de El Escorial el pasado verano -1991-, y el otro se implican mutuamente. Cada uno de ellos son un yo, un tú y un él, correlativamente vinculados para ser autónomos." Se trata de una autonomía implicada íntimamente en una heteronomía, en el mejor sentido, no extrinsecista, de la palabra.

Ricoeur considera que su manera de reflexionar sobre la acción humana hereda la tradición reflexiva del cogito cartesiano a la vez que la amplía. "Mientras en Descartes el punto de partida es el sujeto como yo y como yo pensante, en la narración "superamos" la primera persona [...] La ampliación de la tradición reflexiva consiste en haber pasado del pensamiento a la acción, en haber abordado al hombre como actor de sus actos [...] la cuestión quién hace algo es la cuestión central. Entiendo que el cogito cartesiano es un cogito solitario; hay una sola persona. En cambio, la acción es siempre una acción con otros y, por lo tanto, el problema del otro está implicado en la narración [...] considero que tanto la fenomenología de la intersubjetividad como la teoría de la acción representan una gran conquista $[\ldots] . .3^{23}$

No podemos olvidar que lo que hay latente en todo este movimiento de revisión de la heteronomía, precisamente a favor y no en contra de una recuperación del sujeto, es el hecho de que Ricoeur ha ido ampliando sus orígenes fenomenológicos y transformando la fenomenología en hermenéutica. Queda siempre la preocupación ética por el sujeto dentro de una tradición de filosofía reflexiva y fenomenológica, pero se le impone cada vez más la dificultad de encontrarse este sujeto con lo más originario de sí mismo, si no es por el rodeo de lo otro y los otros, a lo que y a los que "pertenece». Para que el "sí-mismo» se comprenda habrá de reconocerse a sí mismo como un otro y dar el rodeo de lo otro con el fin de llegar a un Sí-mismo que es más punto de llegada que punto de partida. Lo más ca* racterístico de Ricoeur es lo interminable de esta mediación. ${ }^{24}$

También el enfoque del problema religioso y de la hermenéutica bíblica depende para Ricoeur de esta óptica, que podríamos llamar de "autohetero-nomfa». En una reciente entrevista ha dicho clara y directamente: «El problema de Dios entra en nuestra experiencia a través de documentos fundadores como las Escrituras judías y cristianas, el Corán, etc., y nosotros entramos, de este modo, en otro orden de fundación que no es la "fundación por sî", sino una "fundación por otro" (que nos precede). Entrar en esta relación es entrar en el mundo teológico. Un creyente no es alguien que tiene unas determinadas opiniones; es aquel que acepta el ser 
enseñado por los textos fundadores, que entra en una relación de escucha, de lectura y de interpretación de estos textos...». ${ }^{25}$ Pero esta temática ya nos sacaría de los límites del presente artículo.

\section{NOTAS}

1. Paris, Seuil, 1990 .

2. Soi-même comme un autre (en adelante, abreviado: Soi) , p. 12.

3. Soi, p. 48 .

4. Ibid.

5. Soi. p. 56.

6. Soi, p. 73 .

7. Soi, p. 188 .

8. Soi, p. 200.

9. Soi, cap. 7 .

10. Soi, cap. 8 .

11. Soi, cap. 9 .

12. Soi, p. 202.

13. Soi, p. 30.

14. Soi, p. 234.

15. Soi, p. 236.

16. Soi, pp. 350-351.

17. Soi. p. 351.

18. Le confit des interprétations, Paris, Seul, 1969, p. 22.

19. Soi, p. 351-357.

20. Le volontaire et linwolontaire, Paris, Aubier, 1950, 454-455.

21. Soi, p. 251 .

22. Pero sin olvidar la presencia inevitable del mal que, con su escandalo, deshace todas las síntesis simétricas. Esta era una intuición suya desde los dias de La simbólica del mal; hay que tenerlo presente, ya que la simetría del modo de exposición, típico de Ricoeur, podría sugerir a primera vista lo contrario.

23. Entrevista en El Cieno (mayo, 1991), p. 19.

24. Sobre los presupuestos caracteristicos de la tradición filosófica en la que Ricoeur se reconoce inserto ha dicho él mismo en un ensayo descriptivo de la propia trayectoria filosófica, De l'interprétation: acstá en la línea de una filosofia reflexiva; pemanece dentro del movimiento de la fenomenologia husserliana; quiere ser una variante hermenéutica de esta fenomenología (Du texte a l'action, París, Seuil, 1980, p. 25).

25. Id., p. 20 . 